\title{
Use of Bladder Filling to Prevent Urinary System Complications in the Management of Placenta Percreta: a Randomized Prospective Study
}

\author{
Blasenfüllung zur Verhinderung von Komplikationen \\ des Urogenitalsystems in Frauen mit Placenta percreta: \\ eine randomisierte prospektive Studie
}

\section{(C) (1) $\Theta$}

Authors

Hüseyin Çağlayan Özcan ${ }^{1}$, Özcan Balat ${ }^{1}$, Mete Gurol Uğur ${ }^{1}$, Seyhun Sucu ${ }^{1}$, Neslihan Bayramoğlu Tepe ${ }^{1}$,

Tanyeli Güneyligil Kazaz ${ }^{2}$

Affiliations

1 Gaziantep University, School of Medicine, Dept. of Obstetrics and Gynecology, Gaziantep, Turkey

2 Gaziantep University, School of Medicine, Dept. of Biostatistics, Gaziantep, Turkey

Key words

bladder injury, placental implantation abnormality, placenta percreta, urinary system injury

\section{Schlüsselwörter}

Blasenverletzung, plazentare Implantationsstörung, Placenta percreta, Verletzung des Urogenitalsystems

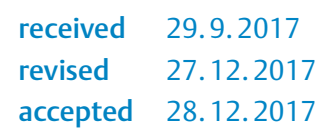

\section{Bibliography}

DOI https://doi.org/10.1055/s-0044-100039

Geburtsh Frauenheilk 2018; 78: 173-178 @ Georg Thieme

Verlag KG Stuttgart · New York | ISSN 0016-5751

\section{Correspondence}

Hüseyin Çağlayan Özcan, MD, Assist. Prof. Gaziantep University, Faculty of Medicine, Department of Obstetrics and Gynecology, Sahinbey En route to Kilis, 27800 Gaziantep, Turkey ozcan.caglayan8@hotmail.com

\section{ABSTRACT}

Introduction The aim of our study was to evaluate the effect of filling the bladder on peripartum genitourinary injuries (especially bladder complications) in women with placenta percreta and to compare patient characteristics.

Material and Methods Our prospective cohort study consisted of pregnant women with placenta percreta who underwent planned cesarean hysterectomy at the Department of
Obstetrics and Gynecology of Gaziantep University Hospital between January 2015 and July 2016. Bladders were filled with $300 \mathrm{ml}$ saline solution to determine surgical borders better and enable dissection of the lower uterine segment without excessive bleeding or unintended injury.

Results A total of 66 women were included in the study: 32 women whose bladders were filled during surgery (filled-bladder group) and 34 women whose bladders were not filled (not filled-bladder group). Comparisons of demographic and obstetrical data, surgical parameters, the need for transfusion, and bladder injury rates revealed no significant differences between the two groups. We did not observe any beneficial effect of filling the bladder on preventing urinary complications compared with the women whose bladders were not filled ( $p=0.339$ ).

Conclusions Filling the bladder with saline solution and mobilization of the bladder from the lower uterine segment did not have a statistically significant beneficial effect on preventing complications of the genitourinary system. But although the beneficial effects were not significant, shorter operation times, shorter postoperative hospital stays, and fewer bladder injuries were noted in patients whose bladders were filled.

\section{ZUSAMMENFASSUNG}

Einleitung Ziel dieser Studie war es, die Auswirkungen einer Blasenfüllung auf peripartale Verletzungen des Urogenitalsystems (insbesondere auf Blasenverletzungen) bei Frauen mit Placenta percreta zu untersuchen und die Patientendaten zu vergleichen.

Material und Methoden Unsere prospektive Kohortenstudie untersuchte Frauen mit Placenta percreta, die sich zwischen Januar 2015 und Juli 2016 einer geplanten Hysterektomie nach erfolgter Sectio caesarea in der Abteilung für Geburtshilfe und Gynäkologie des Gaziantep Universitätsklinikums unterzogen. Die Harnblase wurde jeweils mit $300 \mathrm{ml}$ Kochsalzlösung gefüllt, um sie während des chirurgischen Eingriffs besser abzugrenzen und eine Dissektion des unteren Teils der Gebärmutter ohne übermäßigen Blutverlust oder ungewollte Verletzung zu ermöglichen. 
Ergebnisse Es wurden insgesamt 66 Frauen in die Studie eingeschlossen; bei 32 Frauen wurde die Harnblase vor dem Eingriff gefüllt (gefüllte-Blase-Gruppe) und bei 34 Frauen wurde die Harnblase nicht gefüllt (nicht-gefüllte-Blase-Gruppe). Ein Vergleich der demografischen, gynäkologischen und chirurgischen Daten sowie der Menge an Bluttransfusionen und Harnverletzungen ergab keine wesentlichen Unterschiede zwischen den beiden Gruppen. Die Füllung der Harnblase hatte keine Auswirkungen auf die Verhinderung von Komplikationen des Urogenitalsystems verglichen mit den Frauen, bei de- nen die Harnblase vor dem Eingriff nicht gefüllt wurde $(p=0,339)$.

Schlussfolgerungen Das Füllen der Harnblase mit Kochsalzlösung und die Mobilisierung der Blase von dem unteren Teil der Gebärmutter aus hatte keine statistisch signifikante positive Auswirkung auf die Verhinderung von Komplikationen des Urogenitalsystems. Aber obwohl die positiven Auswirkungen nicht signifikant waren, waren die Operationszeiten und der postoperative Krankenhausaufenthalt kürzer und es gab weniger Harnblasenverletzungen in der Gruppe mit gefüllter Harnblase.

\section{Introduction}

Placenta percreta is a placental adhesive disorder defined by abnormal trophoblastic invasion through the uterine serosa layer and potentially beyond [1]. The reported incidence is approximately $5-7 \%$ of pregnancies with placental adhesive disorders [2]. Increased cesarean section (CS) rates may be one reason for this high incidence. Previous cesarean delivery is the most important risk factor, followed by placenta previa and advanced maternal age [3]. Antenatal diagnosis is helpful to reduce intraoperative urologic complications and the need for blood transfusions [4]. Sonographic and color Doppler examination is generally accepted as the first choice of imaging method for the diagnosis of placental adhesive disorders [5]. In addition to the risk of severe hemorrhage, there is also a risk of unintentional urinary tract (UT) injury, which may result in urinary fistula, ureteral transection, and bladder laceration necessitating partial or total cystectomy [6]. To date, there is no prospective randomized study in the English literature on the effect of filling the bladder during the surgical management of placenta percreta for the prevention of genitourinary system complications.
The aim of our study was to evaluate the effect of filling the bladder on peripartum genitourinary injuries (especially bladder complications) in women with placenta percreta who underwent planned cesarean hysterectomy and to compare patient characteristics.

\section{Patients and Methods}

\section{Study design}

This prospective cohort study included pregnant women with placenta percreta who underwent CS at the Department of Obstetrics and Gynecology of Gaziantep University Hospital between January 2015 and August 2017. All women included in the study gave their written informed consent.

\section{Diagnostic features of Doppler ultrasonography}

Patients were diagnosed by Doppler ultrasonography ( $\bullet$ Fig. 1) in the antenatal period, and the diagnosis was confirmed during surgery performed by the same clinicians. Turbulent flow, the presence of lacunae, increased vascularity at the bladder-placenta
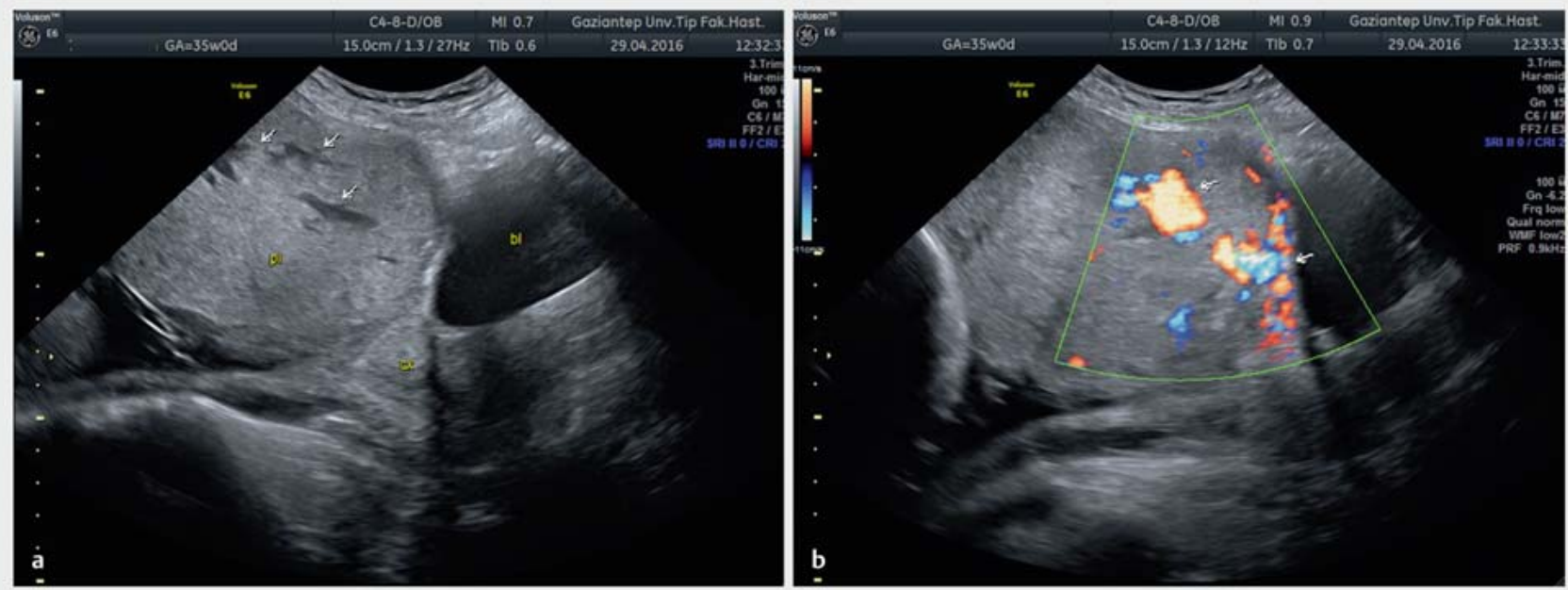

- Fig. 1 a Ultrasonographic image of placenta percreta in a 35-week-old pregnancy. Lacunar structures are indicated by arrows. Note the thin border between uterus and bladder ( $\mathrm{pl}=$ placenta, $\mathrm{cx}=$ cervix, $\mathrm{bl}=$ bladder); $\mathbf{b}$ Doppler ultrasonography image of the same patient with increased vascularity at the vesicouterine junction and lacunar structures. 
border, and damage to myometrial integrity are the standard diagnostic criteria in ultrasonography ( $\bullet$ Fig. 1).

\section{Surgical characteristics}

All specimens obtained were sent for pathological examination. Placenta percreta is defined as the penetration of trophoblastic tissue into all layers of the uterus. All operations were performed under general anesthesia in the dorsal lithotomy position. We included only cases with placenta percreta in whom we performed planned cesarean hysterectomy between the 34th and 36th week of gestation. The decision of the surgeons regarding the appropriate surgical approach for cesarean hysterectomy depended on the severity of disease. Their assessment was based on the presence of increased vascularity in the lower uterine segment/bladder zone and the extent of invasion of the uterine artery.

\section{Bladder filling as a method to determine the vesicouterine border}

Patients were randomized either into the filled-bladder or the not filled-bladder group. The first step in all surgeries was a midline periumbilical incision. The infant was delivered through a fundal vertical uterine incision. The bladder was filled with $300 \mathrm{ml}$ saline (this surgical technique was first defined by the head gynecologic oncologist Prof. Dr. Ozcan Balat) to help determine the borders better and enable dissection of the lower uterine segment without excessive bleeding or unintended injury ( $\vee$ Fig. 2). At the end of the surgical procedure we filled the bladder of all patients with diluted methylene blue to check for the presence of any missed bladder injuries.

\section{Multidisciplinary approach to surgical management}

Bladder complications without ureter involvement were treated by the obstetrician alone or a consulting urologist. A urologist was consulted when patients experienced complications that included ureter involvement. All patients with bladder injuries received antibiotic prophylaxis (cefazolin sodium $1 \mathrm{~g} 2 \times 1 \mathrm{i}$. v.). All patients were managed by a multidisciplinary approach which included an obstetrician, a gynecological oncologist, an anesthetist, an intensive care physician, and a urologist. The same surgical team carried out all operations. The surgical team that participated in this study has the skills to treat the retroperitoneal space, bladder, and ureter, and are experienced in the surgical management of placenta percreta. We planned to prospectively include women into the study for 20 months. The Institutional Ethics Committee approved our study.

\section{Statistical analysis}

Normality of distribution of continuous variables was tested with the Shapiro-Wilk test. Student's t-test was used to compare two independent groups of normally distributed variables. $X^{2}$ test was used to assess the relationships between categorical variables. Statistical analysis was performed using SPSS for Windows, version $11.5^{\circledR}$. A p-value $<0.05$ was considered statistically significant.

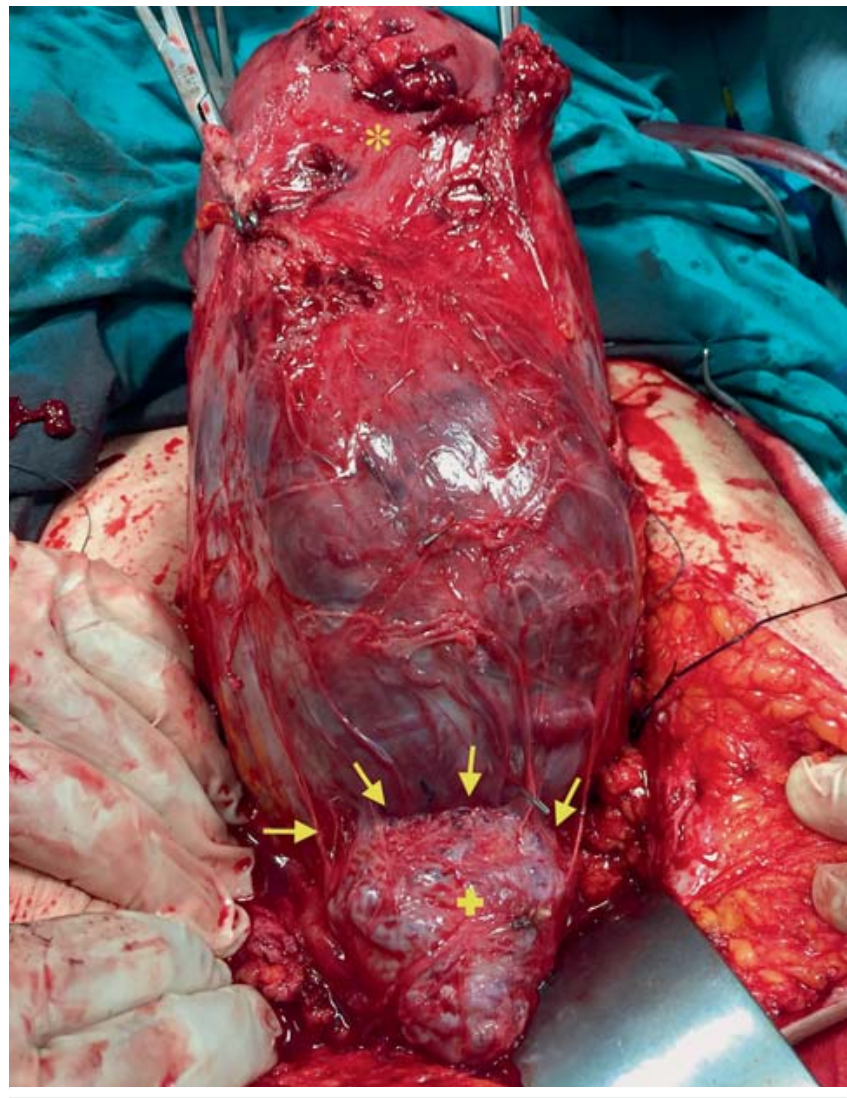

- Fig. 2 Intraoperative image of placenta percreta in which the bladder was filled with $300 \mathrm{ml}$ saline (asterisk, arrows, and plus sign indicate the uterus, vesicouterine border and bladder, respectively).

\section{Results}

\section{Patient characteristics}

A total of 66 women were included in the study: 32 women whose bladders were filled with saline before surgery (filled-bladder group) and 34 women whose bladders were not filled before surgery (not filled-bladder group). The mean age of all women was $32.62 \pm 4.49$ years (range: $23-41$ years). Mean body mass index $\left(\mathrm{kg} / \mathrm{m}^{2}\right)$ was $28.38 \pm 1.52$ (range: $\left.25-31\right)$. Parity, gravidity and gestational age (weeks) at surgery were $3.41 \pm 1.12$ (range: $1-7$ ), $4.86 \pm 1.65$ (range: $2-10$ ) and $35.35 \pm 3.27$ (range: $22-40$ ), respectively. Six women $(9.1 \%)$ had had 2 previous cesarean sections and 60 women $(90.9 \%)$ had had $>3$ previous CS.

\section{Operative outcomes}

Mean preoperative and postoperative hemoglobin levels of women were $10.91 \pm 1.63 \mathrm{~g} / \mathrm{dl}$ (range: $5.2-13.7$ ) and $10.47 \pm 1.69 \mathrm{~g} / \mathrm{dl}$ (range: $2.4-13.8$ ), respectively. Erythrocyte suspensions and fresh frozen plasma replacements of $2.97 \pm 1.93$ units (range: $0-8$ ) and $2.58 \pm 1.82$ units (range: $0-7$ ) were transfused, respectively. The mean operation time was $91.36 \pm 33.78$ minutes (range: 60210). The mean length of hospital stay for all women was $5.09 \pm 4.22$ days (range: $1-19$ ). 
- Table 1 Comparison of patient groups with filled and unfilled bladders.

\begin{tabular}{|c|c|c|c|}
\hline & Filled bladder $(n=32)$ & Not filled bladder $(n=34)$ & $\mathbf{p}$ \\
\hline \multicolumn{4}{|l|}{ Maternal characteristics } \\
\hline - Age (years)* & $32.31 \pm 4.25$ & $32.91 \pm 4.74$ & 0.591 \\
\hline - $\mathrm{BMI}\left(\mathrm{kg} / \mathrm{m}^{2}\right)^{*}$ & $28.28 \pm 1.53$ & $28.47 \pm 1.52$ & 0.616 \\
\hline - Gravidity (n)* & $4.66 \pm 1.15$ & $5.06 \pm 1.69$ & 0.265 \\
\hline - Parity $(n)^{*}$ & $3.34 \pm 0.97$ & $3.47 \pm 1.26$ & 0.650 \\
\hline - Previous cesarean section $(n)^{*}$ & $3.25 \pm 0.8$ & $3.15 \pm 0.66$ & 0.570 \\
\hline - Gestational age (weeks)* & $35.5 \pm 2.72$ & $35.47 \pm 4.06$ & 0.973 \\
\hline - Operation time (minutes)* & $85.31 \pm 35.01$ & $97.06 \pm 32.05$ & 0.160 \\
\hline Postoperative stay in hospital (days) ${ }^{*}$ & $4.97 \pm 3.86$ & $5.21 \pm 4.59$ & 0.822 \\
\hline ICU admission, $\mathrm{n}(\%)$ & $8(25)$ & $8(23.5)$ & 0.889 \\
\hline \multicolumn{4}{|l|}{ Blood transfusion (units)* } \\
\hline - Erythrocytes & $2.97 \pm 2.09$ & $2.97 \pm 1.82$ & 0.997 \\
\hline - Fresh frozen plasma & $2.47 \pm 1.83$ & $2.68 \pm 1.84$ & 0.647 \\
\hline Bladder injury, n (\%) & $7(21.9)$ & $11(32.4)$ & 0.339 \\
\hline
\end{tabular}

\section{Influence of bladder filling on outcomes}

Comparisons of demographic, obstetrical and surgical data, the need for transfusion and bladder injury rates for the two groups (filled-bladder group vs. not filled-bladder group) revealed no significant differences. Data are shown in $>$ Table 1. We did not observe any effect of filling the bladder on intraoperative or postoperative complications when compared with cases whose bladders were not filled $(p=0.339)$. The complications reported for the women in our study, listed from the most common to the least common, were bladder injury (69.2\%), pelvic hematoma leading to re-laparotomy (15.3\%), ureteral injury (3.8\%), external iliac vein injury (3.8\%), pelvic hematoma follow-up (3.8\%), and ileus $(3.8 \%)$ ( Table 2 ).

\section{Discussion}

The incidence of placental invasion abnormalities is increasing and presents surgical and diagnostic challenges for obstetricians. Our hospital is the biggest regional tertiary referral center for complicated obstetrical surgery in southeastern Turkey. The high rate of cases with placenta percreta can therefore be explained by the high rates of referral. A history of multiple CS or placenta previa increases the risk of placental invasion abnormalities [7]. A high number (>3) of previous cesarean sections is an obvious risk factor for complications; in addition, the complication rate for patients with placenta percreta is much higher due to deep placental and vascular infiltration.

We did not detect any significant difference in the number of previous CS on the presence or absence of complications. Given the high morbidity and mortality rates associated with placental adhesive disorders, antenatal diagnosis improves the outcome [8]. The sensitivity and specificity for a diagnosis of placental invasion abnormalities diagnosed using ultrasound is $80-90 \%$ in spe-
- Table 2 Number and percentage of intraoperative complications.

\begin{tabular}{|l|l|c|}
\hline & $\begin{array}{l}\text { Filled } \\
\text { bladder (\%) }\end{array}$ & $\begin{array}{l}\text { Not filled } \\
\text { bladder (\%) }\end{array}$ \\
\hline Intraoperative complication & & \\
\hline - Bladder injury & $7(21.9)$ & $11(32.4)$ \\
\hline - Ureteral injury & $1(3.1)$ & 0 \\
\hline - External iliac vein injury & 0 & $1(2.9)$ \\
\hline $\begin{array}{l}\text { Postoperative complication } \\
\text { - Pelvic hematoma on } \\
\text { follow-up }\end{array}$ & $1(3.1)$ & 0 \\
\hline $\begin{array}{l}\text { - Pelvic hematoma leading } \\
\text { to re-laparatomy }\end{array}$ & $2(6.3)$ & $2(5.9)$ \\
\hline - lleus & 0 & $1(2.9)$ \\
\hline
\end{tabular}

cialized centers [9], but these rates are likely to be much lower for standard providers of obstetrical care. In our study, we did not include the records of patients with a false-positive diagnosis of placenta percreta based on antenatal ultrasonography examination. Analysis of the sensitivity and specificity of ultrasonography is therefore beyond the scope of our study. Poor access to ultrasound and limited experience on the part of the obstetrician are factors reducing the likelihood of making an antenatal diagnosis. Turbulent flow and the presence of lacunae, increased vascularity at the bladder-placenta border, and damage to myometrial integrity are the standard diagnostic criteria in ultrasonography [10]. A planned hysterectomy carried out by an experienced team is the recommended procedure for the management of placental adhesive disorders [11]. Segment resection of the lower uterine seg- 
ment, hysterectomy, or leaving the placenta in situ to be resorbed are alternative approaches for the management of placental invasion anomalies [12]. In most patients with placenta percreta aggressive treatment is a must. Massive blood transfusions, urological injuries, and infections are major issues in this complicated treatment [13].

Massive and/or persistent hemorrhage, bladder injury, ureteral damage, and bowel injury are the most common complications resulting in admission to the intensive care unit [14]. Eller et al., reporting on 76 cases, found that blood transfusion was required in more than $80 \%$ of cases [15]. This rate is comparable with the figures in our study (91\%). Maternal and prenatal fetal deaths from massive hemorrhage are the worst scenarios in women with placenta percreta. There was one maternal death in our study (1.5\%). Bladder injury, ureteral dilation, ureteral transection, and fistula between the bladder and cervix are known urological complications of placenta percreta [16].

The incidence of unintentional genitourinary injuries with placental adhesive disorders is reported to be as high as $29 \%$ [17]. Bladder injury is the most common surgical complication in cases with adhesive placental disorders and this finding is related to the uncertain borders between the bladder and the adhesive tissue that occur as a result of placental invasion [18]. Ureteral injury rates can vary from 10 to $15 \%$ [17]. There are many reports in the literature aiming to decrease these serious urological complications. Preserving the bladder border is an important step in the surgical approach to treat invasive placental disorders. Additional procedures such as filling the bladder with saline, administering intravenous dye, or instilling sterilized milk are used to preserve the bladder or determine bladder injury [19]. In our study, bladder and ureteral injury rates were 27.2 and $1.5 \%$, respectively. The enormously increased risk of bladder injury in placenta percreta cases became much more obvious when we retrospectively analyzed the rate of bladder injuries after normal CS in our clinic, which was around $0.26 \%$ (12/4801) over a period of five years.

In the majority of placental adhesive disorders, the placenta invades the lower uterine segment and/or the cervix. There are a number of approaches to treat placental invasive disorders. The treatment of choice is primarily surgical and consists of hysterectomy [18]. Results of a questionnaire study issued to members of the Society of Perinatal Obstetricians stated that $93 \%$ of cases with placenta percreta were managed by total hysterectomy [20]. In line with this finding we preferred total hysterectomy as the surgery of choice for all hysterectomies in our study.

Maternal morbidity is a significant problem for women with placenta percreta. Urinary tract injury is more common during hysterectomies for placental invasive disorders than for hysterectomies performed for gynecological reasons (29 vs. $4.8 \%$ ) [21]. Performing different types of procedures can prevent inadvertent genitourinary injuries. Subtotal hysterectomy, delayed hysterectomy, and placing ureteric catheters before CS are the most significant surgical approaches [22]. We used a specific surgical approach in our study that involved both filling the bladder with saline and mobilization of the bladder following delivery of the fetus. Statistical analysis revealed that, on average, 14.3 women would have to undergo filling of their bladder (rather than no filling) to prevent one additional patient suffering an additional blad- der injury. It is imperative on any obstetric surgeon treating placenta percreta to develop an individualized protocol that includes management of maternal hemorrhage. The most important step is detecting pregnant women at risk for placenta percreta and directing them to appropriate centers in case of emergency. There is also an evident need to define the most appropriate surgical techniques and approaches. Our study is just another such step.

As far as we know, our study is the largest prospective study in the English literature on filling the bladder as a surgical approach in the management of placenta percreta. The limitations of our study include the relatively small number of women treated, given the fact that the number needed to treat to prevent further bladder injury is 14.3. Because of the absence of conclusive data, the big question remains on to how to choose the appropriate surgical approach for a specific placental invasive disorder.

\section{Conclusion}

Filling the bladder with saline and mobilization of the bladder from the lower uterine segment did not have a statistically significant beneficial effect on preventing complications of the urinary system (especially of the bladder). But although the results were not significant, shorter operation times, shorter postoperative stays in hospital, and fewer bladder injuries were observed in patients whose bladders were filled prior to surgery. Depending on his or her surgical experience, the surgeon may prefer to fill the bladder prior to surgery, and this approach may be considered, especially in cases with placenta percreta where anatomical landmarks are unclear.

\section{Funding}

Our study did not receive any funding.

\section{Conflict of Interest}

The authors declare that they have no conflict of interest.

\section{References}

[1] Garmi G, Salim R. Epidemiology, etiology, diagnosis, and management of placenta accreta. Obstet Gynecol Int 2012; 2012: 873929

[2] Miller DA, Chollet JA, Goodwin TM. Clinical risk factors for placenta previa-placenta accreta. Am J Obstet Gynecol 1997; 177: 210-214

[3] Wu S, Kocherginsky M, Hibbard JU. Abnormal placentation: twenty-year analysis. Am J Obstet Gynecol 2005; 192: 1458-1461

[4] Abuhamad A. Morbidly adherent placenta. Semin Perinatol 2013; 37 359-364

[5] Warshak CR, Eskander R, Hull AD et al. Accuracy of ultrasonography and magnetic resonance imaging in the diagnosis of placenta accreta. Obstet Gynecol 2006; 108: 573-581

[6] Faranesh R, Shabtai R, Eliezer $\mathrm{S}$ et al. Suggested approach for management of placenta percreta invading the urinary bladder. Obstet Gynecol 2007; 110: 512-515

[7] Silver RM, Landon MB, Rouse DJ et al. Maternal morbidity associated with multiple repeat cesarean deliveries. Obstet Gynecol 2006; 107: 12261232 
[8] Koai E, Hadpawat A, Gebb J et al. Clinical outcomes and efficacy of antenatal diagnosis of placenta accreta using ultrasonography and magnetic resonance imaging. Obstet Gynecol 2014; 123 (Suppl. 1): 61S

[9] Comstock CH, Bronsteen RA. The antenatal diagnosis of placenta accreta. BJOG 2014; 121: 171-181

[10] Chou MM, Tseng J], Ho ES et al. Three-dimensional color power Doppler imaging in the assessment of uteroplacental neovascularization in placenta previa increta/percreta. Am J Obstet Gynecol 2001; 185: 1257-1260

[11] Eller AG, Bennett MA, Sharshiner M et al. Maternal morbidity in cases of placenta accreta managed by a multidisciplinary care team compared with standard obstetric care. Obstet Gynecol 2011; 117: 331-337

[12] Clausen C, Stensballe J, Albrechtsen CK et al. Balloon occlusion of the internal iliac arteries in the multidisciplinary management of placenta percreta. Acta Obstet Gynecol Scand 2013; 92: 386-391

[13] Aggarwal R, Suneja A, Vaid NB et al. Morbidly adherent placenta: a critical review. J Obstet Gynaecol India 2012; 62: 57-61

[14] Bretelle F, Courbiere B, Mazouni C et al. Management of placenta accreta: morbidity and outcome. Eur J Obstet Gynecol Reprod Bio 2007; 133 : 34-39
[15] Eller AG, Porter TF, Soisson P et al. Optimal management strategies for placenta accreta. BJOG 2009; 116: 648-654

[16] Caliskan E, Tan O, Kurtaran V et al. Placenta previa percreta with urinary bladder and ureter invasion. Arch Gynecol Obstet 2003; 268: 343-344

[17] Tam Tam KB, Dozier J, Martin JN. Approaches to reduce urinary tract injury during management of placenta accreta, increta, and percreta: a systematic review. J Matern Fetal Neonatal Med 2012; 25: 329-334

[18] Clausen C, Lonn L, Langhoff-Roos J. Management of placenta percreta: a review of published cases. Acta Obstet Gynecol Scand 2014; 93: 138143

[19] Shellhaas CS, Gilbert S, Landon MB et al. The frequency and complication rates of hysterectomy accompanying cesarean delivery. Obstet Gynecol 2009; 114: 224-229

[20] O'Brien JM, Barton J, Donaldson E. The management of placenta percreta: conservative and operative strategies. Am J Obstet Gynecol 1996; 175: $1632-1638$

[21] Vakili B, Chesson RR, Kyle BL et al. The incidence of urinary tract injury during hysterectomy: a prospective analysis based on universal cystoscopy. Am J Obstet Gynecol 2016; 192: 1599-1604

[22] Norris BL, Everaerts W, Posma E et al. The urologist's role in multidisciplinary management of placenta percreta. BJU Int 2016; 117: 961-965 